\title{
The Influence of Cooling Rate on the Microstructure and Microsegregation in Al-30Sn Binary Alloy
}

\author{
A. R. Valizadeh • A. R. Kiani-Rashid • \\ M. H. Avazkonandeh-Gharavol • E. Z. Karimi
}

Received: 21 December 2012/Revised: 11 February 2013/Accepted: 16 February 2013/Published online: 6 March 2013

(C) Springer Science+Business Media New York and ASM International 2013

\begin{abstract}
Aluminum-tin alloys have wide industrial uses, especially in tribological applications. Their structure is consisted of $\mathrm{Al}-\alpha$ dendrites (bearing the mechanical load) surrounded by Sn-rich interdendritic layers that function as a solid lubricant. Despite extensive research on solidification behavior of Al-Sn and Al-Sn-based alloys, microsegregation is not yet fully understood. The aim of this article is to study the effect of cooling rate on the microsegregation of $\mathrm{Al}-30 \mathrm{wt} \% \mathrm{Sn}$. Three cooling rates including $3.5,12.3$, and $95.8 \mathrm{~K} / \mathrm{s}$ were achieved by using three various molds made of sand, brass, and water-cooled brass with the same respective die hole geometries. The results showed that the microstructure becomes much finer with increasing cooling rate. The minimum concentration of $\mathrm{Sn}$ in Al was increased by increasing cooling rate approximately four times of equilibrium concentration. The hardness increased mainly as a result of microstructure refinement.
\end{abstract}

Keywords Aluminum - Tin - Cooling rate .

Microstructure $\cdot$ Microsegregation

\footnotetext{
A. R. Valizadeh $(\bowtie)$

Department of Materials Engineering, Science and Research Branch, Islamic Azad University, Tehran, Iran e-mail: engr.alireza.valizadeh@gmail.com
}

\author{
A. R. Kiani-Rashid · M. H. Avazkonandeh-Gharavol \\ Department of Materials Engineering and Metallurgy, Faculty of \\ Engineering, Ferdowsi University of Mashhad, Mashhad, Iran \\ E. Z. Karimi \\ Department of Metallurgy, Islamic Azad University, Mashhad \\ Branch, Mashhad, Iran
}

\section{Introduction}

Aluminum-tin alloys are well known for having excellent tribological and mechanical properties making them suitable for engineering applications, particularly in combustion engine pistons and cylinder liners [1]. As can be seen in Fig. 1 [2], the solid solubility limit of $\mathrm{Sn}$ in $\mathrm{Al}$ is below $0.09 \mathrm{wt} \% \mathrm{Sn}(0.02 \mathrm{at} \% \mathrm{Sn})$; therefore, Al-Sn alloys, which have $\mathrm{Sn}$ contents higher than $0.09 \mathrm{wt} \%$, are formed by $\mathrm{Sn}$ particles spread over a continuous Al-rich matrix. This type of structural morphology determines the good tribological behavior of the alloy because of the tough Al-rich matrix, which is more resistant to high mechanical loads. The structure acts in combination with the Sn particles that function as solid lubricants [3]. Conventional Babbitt alloys, especially lead bronzes alloys, are increasingly being replaced by aluminum alloys, particularly in the automobile industry [4]. Such alloys are also recommended as anodic protective coatings for anti-corrosive protection of steel [5].

Cruz et al. $[1,3,6]$ worked on the solidification structure of $\mathrm{Al}-\mathrm{Sn}$ alloys directionally solidified under transient heat flow conditions. Combined theoretical and experimental approaches have been used to quantitatively determine thermal variables such as (a) transient metal/mold heat transfer coefficients, (b) tip growth rates, (c) thermal gradients, (d) tip cooling rates, and (e) local solidification time. This study focuses on the dependence of dendrite arm spacing on the alloy solute content and thermal variables [1]. The effects of cooling rate on solidification structure and hence tensile and wear properties were also investigated [3]. Cruz et al. [6] also studied the inverse (macro-) segregation of $\mathrm{Al}-23 \% \mathrm{Sn}$ directionally solidified under transient heat flow conditions experimentally and by finite volume numerical modeling [6]. Kliauga and Ferrante [7] added $0.5 \mathrm{wt} \% \mathrm{Sn}$ to $\mathrm{A} 356$ commercial $\mathrm{Al}$ alloy and 


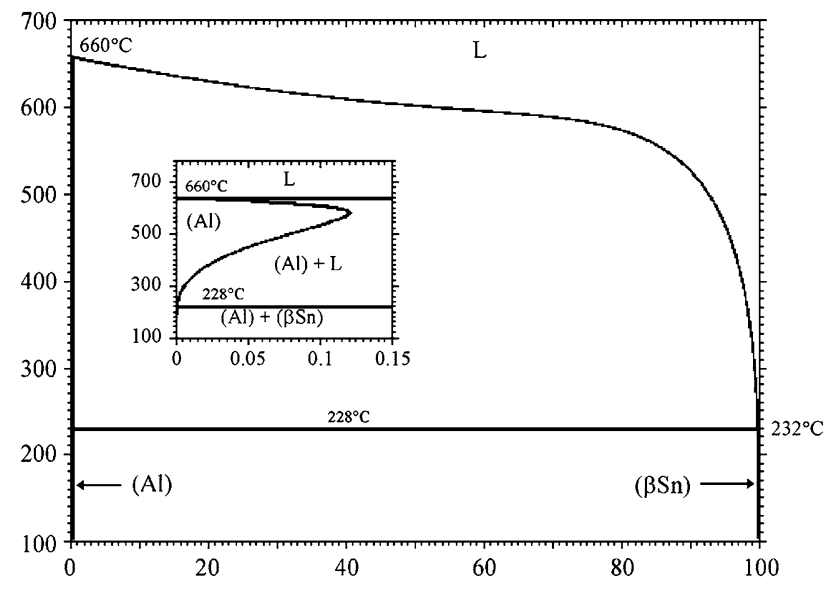

Fig. 1 Al-Sn phase diagram [2]

Fig. 3 Optical micrographs showing microstructures of samples casted in $(\mathbf{a}, \mathbf{b})$ sand; (c, d) metal; and (e, f) water-cooled metal molds with different magnifications. The third phase and the holes are indicated by white and black arrows, respectively

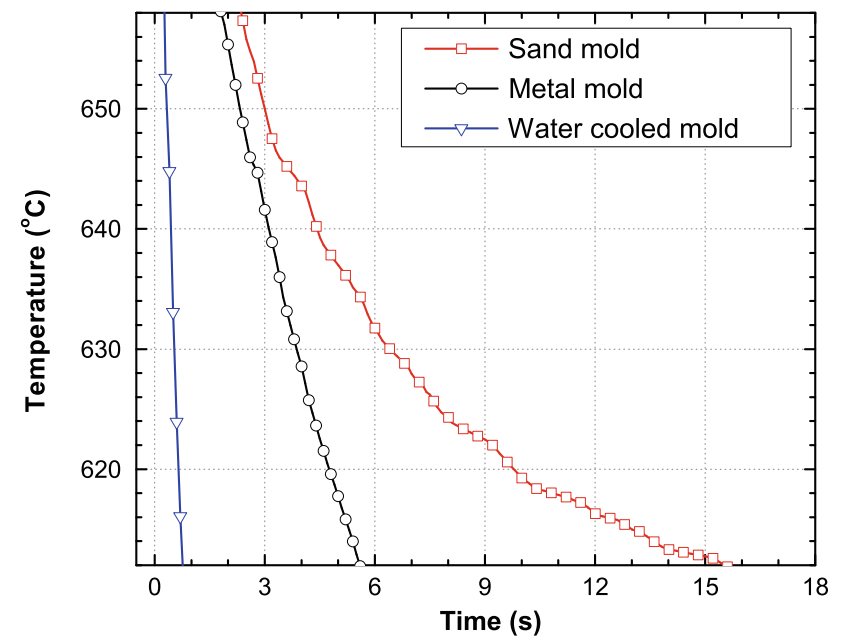

Fig. 2 Measured cooling curves for the different cooling conditions in the range $660-610^{\circ} \mathrm{C}$
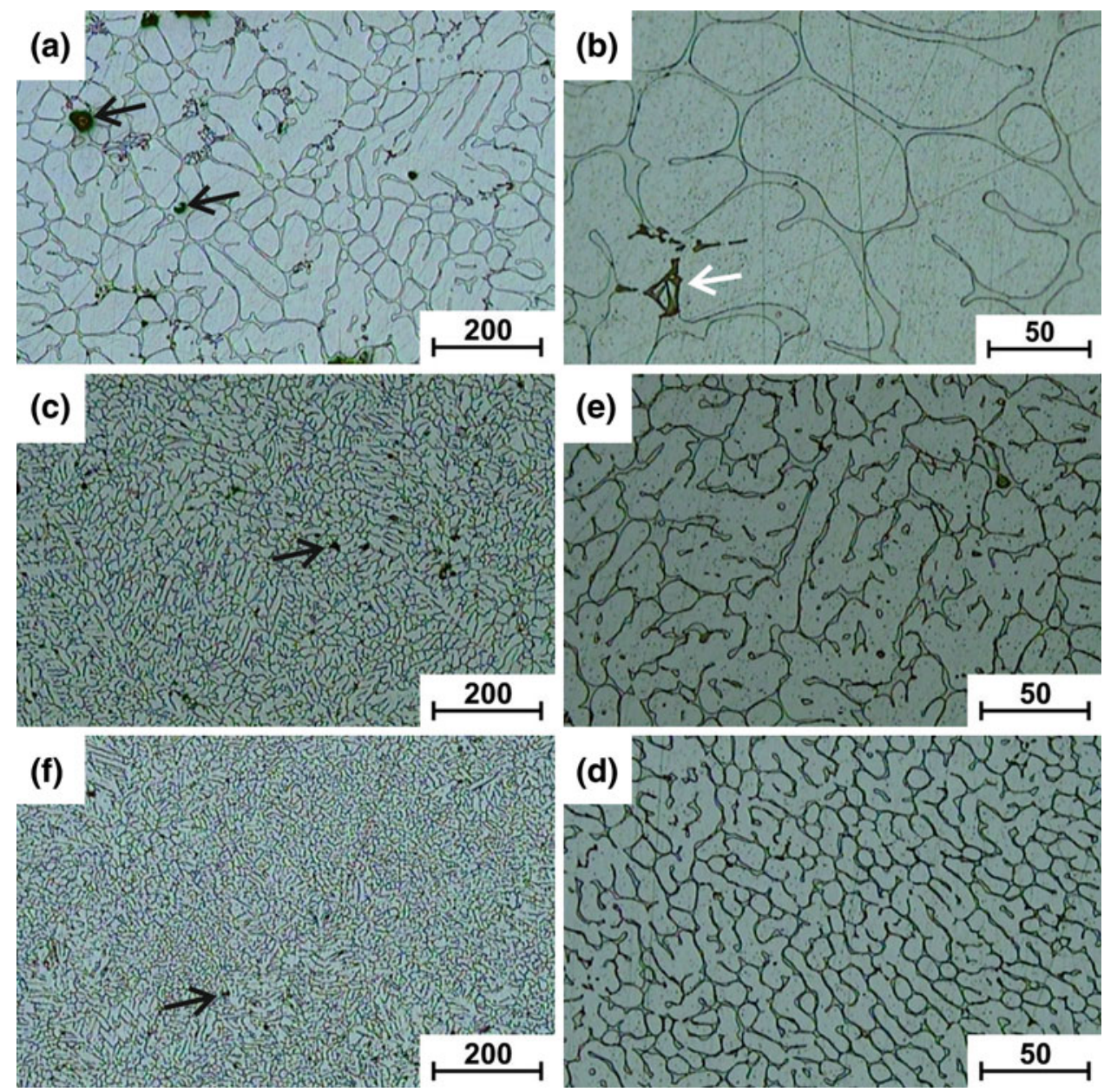

observed that $\mathrm{Sn}$ reduced the contiguity and the growth kinetics of the $\mathrm{Al}-\alpha$ particles and contributed to grain orientation randomizing.

Extensive research has been conducted on different aspects of solidification processing of Al-Sn and Al-Sn-based alloys including dendrite arm spacing [1, 3, 8], simulation of structure formation during solidification [6,9], columnar-toequiaxed transition in directional solidification $[10,11]$, and on the effects of other alloying elements on the solidification behavior of binary Al-Sn alloys [12-16]. Despite the wide 


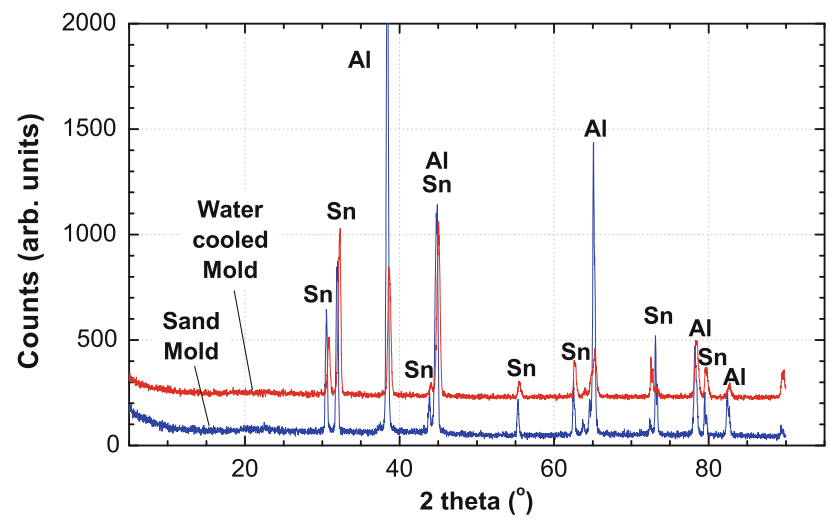

Fig. 4 XRD spectra from the samples produced with the two extreme cooling conditions

use of Al-Sn alloys for engineering applications, studies conducted on the microsegregation of such materials are few. Increasing cooling rate was reported to increase solid solubility and hence decrease the microsegregation and therefore the second phase content $[17,18]$. More alloying elements will remain in the primary $\mathrm{Al}-\alpha$ dendrites that strengthen them by solid solution hardening. Increasing cooling rate also decreases the scale of microstructure, which in turn increases the strength of the alloy. Both these effects are beneficial because the application of the current alloy in tribological applications needs to be stronger. Cooling rate range in industrial casting processes can be as low as $0.01 \mathrm{~K} / \mathrm{s}$ for massive sand casting, and also can be as high as $10^{5} \mathrm{~K} / \mathrm{s}$ upon rapid solidification of granules and flakes. The majority of casting processes, however, operate in the range of cooling rates between 0.1 and $20 \mathrm{~K} / \mathrm{s}$ [19]. The aim of the current research is to study the effect of cooling rate on the microstructure and specially microsegregation of the $\mathrm{Al}-\mathrm{Sn}$ binary alloy in a common cooling rate range in industry.

\section{Experimental Procedure}

$\mathrm{An} \mathrm{Al}$ alloy containing approximately $30 \mathrm{wt} \% \mathrm{Sn}$ was produced by melting high purity $\mathrm{Al}(99.99 \%)$ and $\mathrm{Sn}$ (purity higher than $99.5 \%$ ) by a resistance furnace in air in an alumina crucible. The chemical composition of the alloys was determined using atomic absorption technique. The alloy was cast using three different mold materials to produce three different cooling rates. A silica sand mold was used for low cooling rate and a metallic (brass) mold with and without water circulation was used as two other cooling conditions with higher cooling rates. All molds had a cylindrical hole with the same size of $D \times H: 2 \times 2 \mathrm{~cm}$. During casting, the cooling curves were saved by a data acquisition system using a $0.5 \mathrm{~mm}$ diameter $\mathrm{K}$ thermocouple. After being cooled to

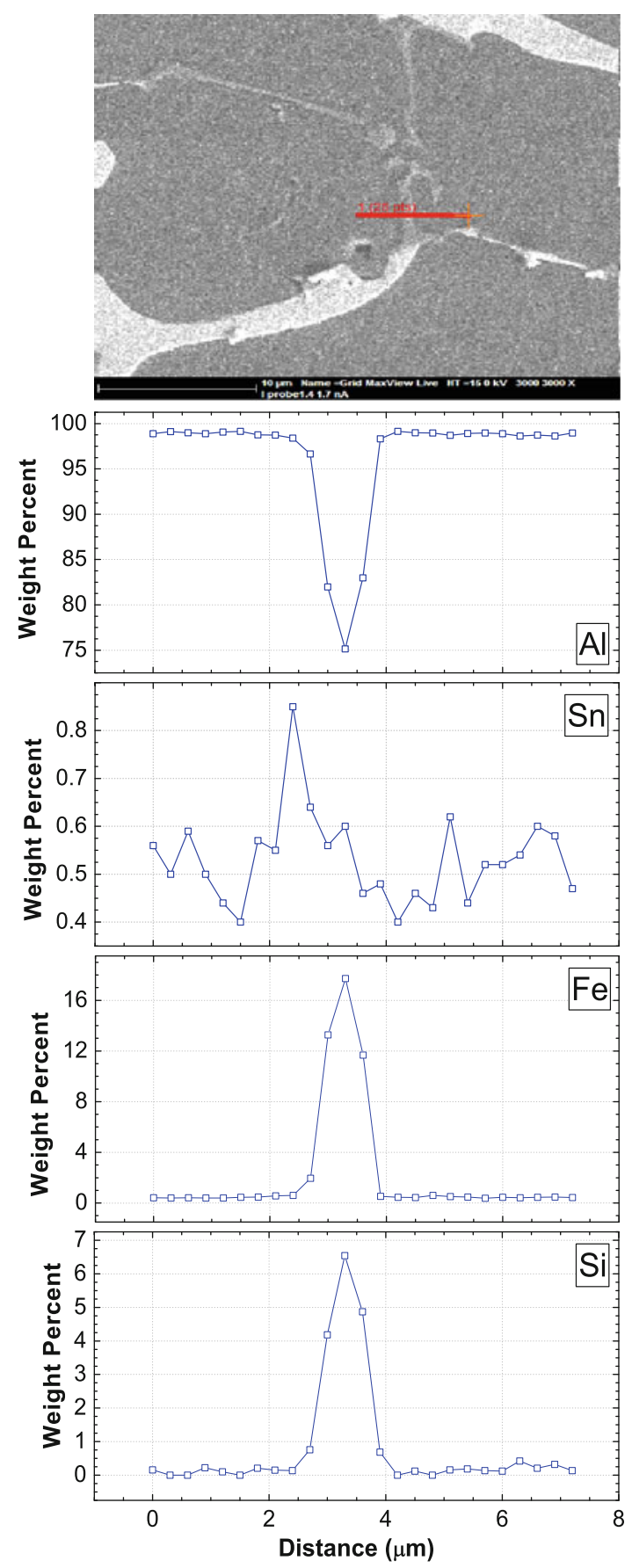

Fig. 5 Elemental concentration profiles for third type phases in sample casted in sand mold

room temperature, samples were cross sectioned and prepared for metallography, microhardness, electron probe micro-analysis (EPMA), and x-ray diffraction (XRD) examination. Metallography of samples was performed according to conventional procedures, with grinding and then polishing with micron sized diamond paste on a rotating wheel. The samples were etched in Keller's reagent to reveal their microstructures. The microstructures of etched samples 


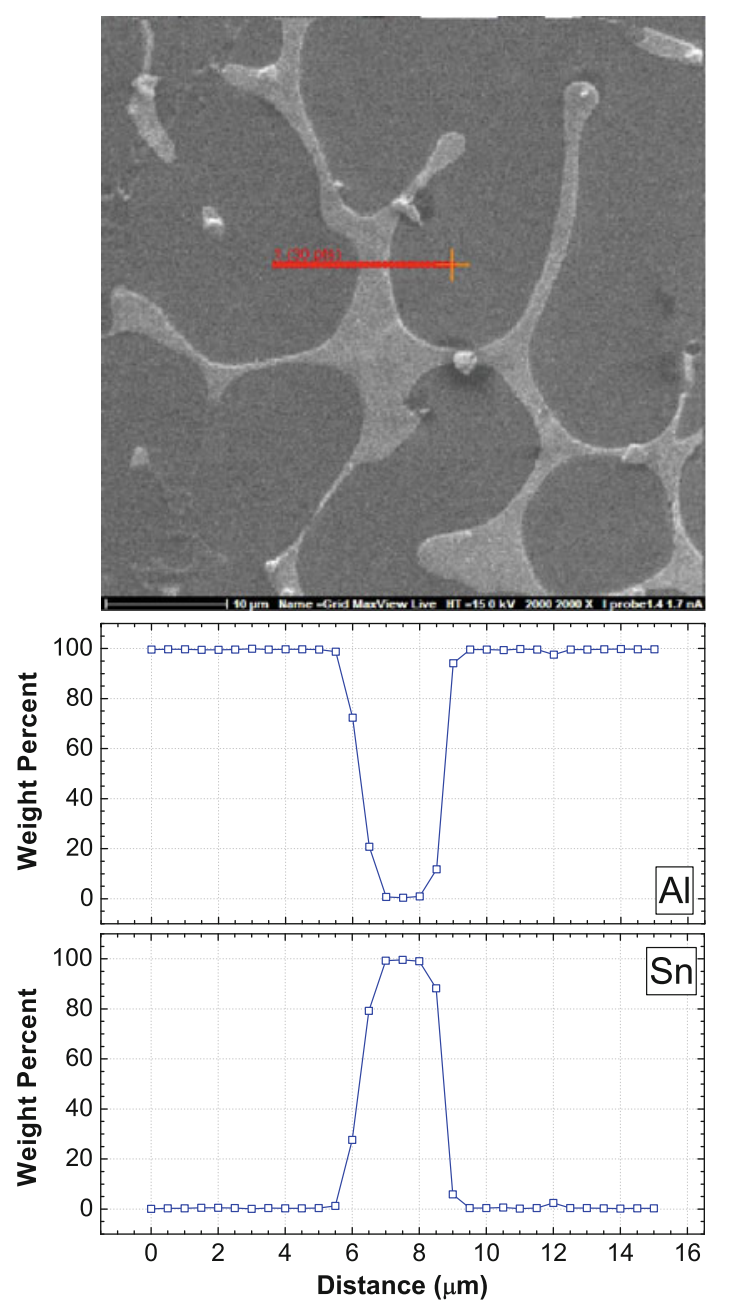

Fig. 6 SEM micrograph and line scan analysis for the sample casted in sand mold

were studied via light microscopy. The quantity of the second phase was measured by processing light micrographs. The hardness of the samples was determined using a microhardness tester with a $200 \mathrm{~g}$ load. XRD was used to identify the phases present in the as-cast microstructure. The grain size of the samples was also measured from XRD spectra. Microsegregation was studied with EMPA line scans on etched samples.

\section{Results and Discussion}

The chemical composition as determined by atomic absorption analysis was $69.93 \mathrm{wt} \% \mathrm{Al}$ and $30.02 \mathrm{wt} \% \mathrm{Sn}$; the impurity level was approximately $0.05 \mathrm{wt} \%$. The cooling rate is calculated in the range of $660-610{ }^{\circ} \mathrm{C}$ according to the curves shown in Fig. 2. This figure shows that changing the mold material from sand to water-cooled brass significantly changed the cooling rate of the melt.
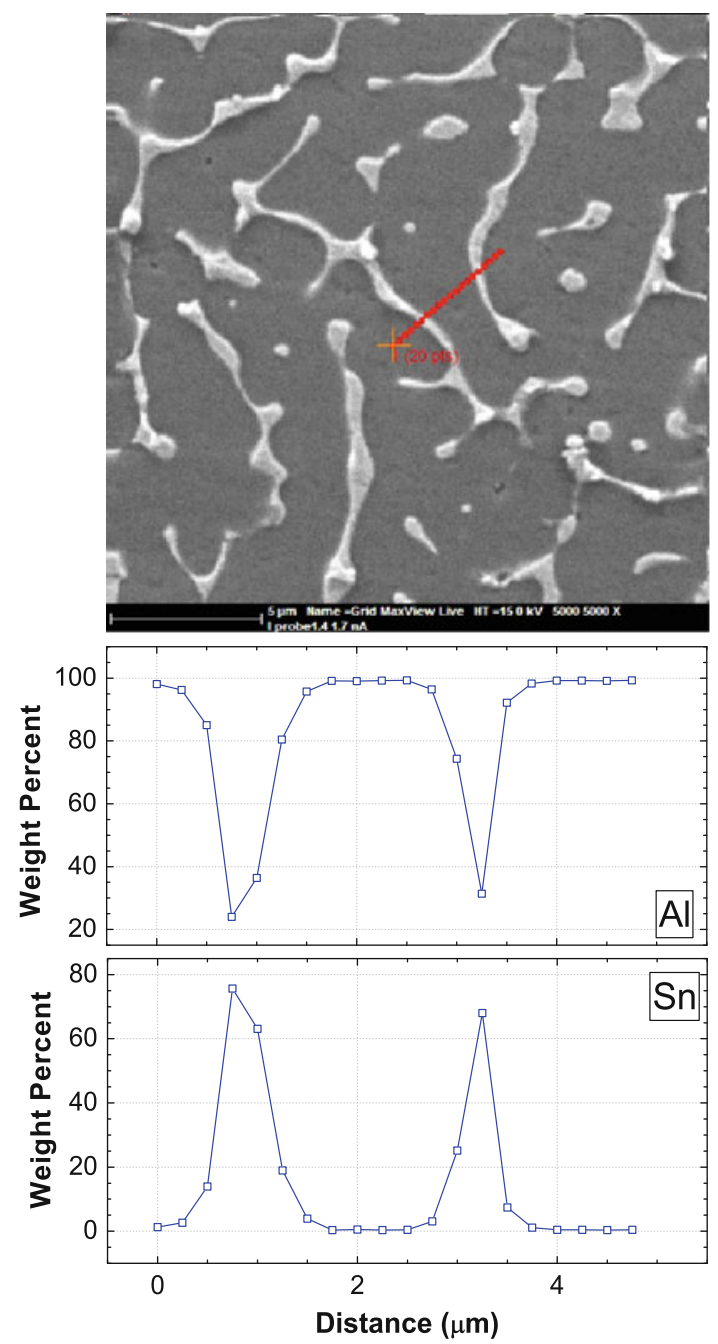

Fig. 7 SEM micrograph and line scan analysis for the sample casted in metal mold

The cooling rates calculated from the cooling curves were $3.5,12.3$, and $95.8 \mathrm{~K} / \mathrm{s}$ for the samples casted in sand, metal, and water-cooled metal mold, respectively.

The microstructures of all samples are shown in Fig. 3. The microstructure consists of two phases: a dendritic Al-rich phase and a Sn-rich interdendritic phase. These phases were also confirmed by XRD analysis that consisted of two peak sets as indicated in Fig. 4. The microstructure became finer with increasing cooling rate, as shown in Fig. 3. Increasing the cooling rate increased the undercooling of the melt and the solidification began at a lower temperature. At lower temperatures, however, the diffusion was limited and the rate of nucleation was increased because of higher driving forces. The structures therefore became finer as the cooling rate increased.

Many large pores, which were mostly localized to the Sn-rich phase, were observed in the sand mold casting sample. Increasing the cooling rate reduced both the number and the size of these pores. This sample also 


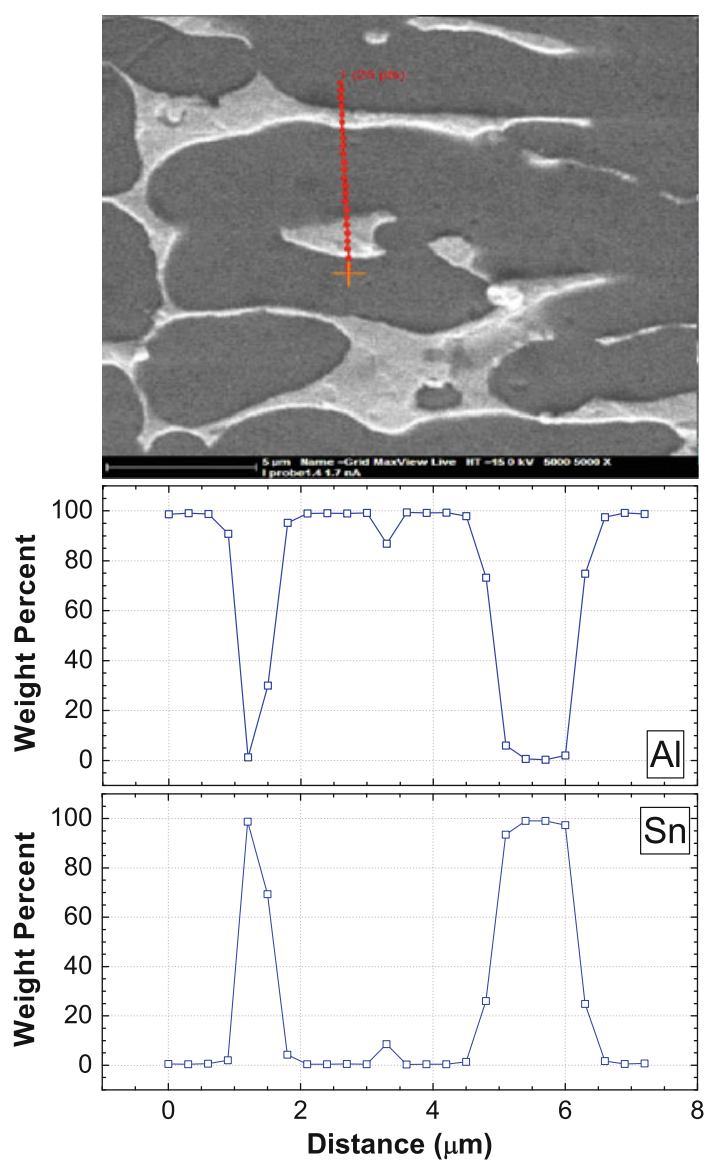

Fig. 8 SEM micrograph and line scan analysis for the sample casted in water-cooled metal mold

Table 1 Structural features of samples

\begin{tabular}{lclll}
\hline Mold & $\begin{array}{l}\text { Coolingrate } \\
(\mathrm{K} / \mathrm{s})\end{array}$ & $\begin{array}{l}\text { Second phase } \\
\text { content }\end{array}$ & $\begin{array}{l}C_{\min } \\
(\mathrm{wt} \%)\end{array}$ & $\begin{array}{l}\text { Vickers } \\
\text { hardness }\end{array}$ \\
\hline Sand mold & 3.5 & 16.6 & 0.08 & 29.1 \\
$\begin{array}{c}\text { Brass mold } \\
\begin{array}{c}\text { Water-cooled } \\
\text { brass mold }\end{array}\end{array}$ & 12.3 & 18.5 & 0.34 & 31.1 \\
\hline
\end{tabular}

contains a third phase in addition to the Al- and Sn-rich phases. This phase has a plate-like morphology with Chinese script shape. The EPMA results shown in Fig. 5 revealed that this phase contains iron and silicon, in addition to aluminum and tin. The $\mathrm{Sn}$ concentration profile shows no preferential segregation to this phase. All samples were cast from the same master alloy, but this phase was only observed in the sand mold sample. It is possible that silica from the mold became incorporated in the alloy. The concentration of this phase was low (approximately $4 \%$ ) and thus it was not detected via XRD.

The results of EPMA line scan analyses are presented in Figs. 6-8. This analysis was used to compare the level of microsegregation for the different cooling rates. Minimum solute concentration was used as the criterion of microsegregation; with increasing minimum concentration of $\mathrm{Sn}$ in Al dendrites, the level of microsegregation was decreased. The minimum concentration for each cooling rate is reported in Table 1. In the lowest cooling rate, the $\mathrm{Sn}$ content of the $\mathrm{Al}$ dendrites was $0.08 \mathrm{wt} \%$ which was similar to the theoretical value of $0.09 \mathrm{wt} \%$. By increasing the cooling rate, the minimum Sn concentration was increased approximately four times up to $0.34 \mathrm{wt} \%$. The microsegregation first decreased and then increased again in the water-cooled brass mold.

The results of the hardness test are also shown in Table 1. Hardness increased monotonically with increasing cooling rate. The only parameter that was correlated with hardness was microstructure refinement (Fig. 3; Table 1). The grain size calculated from XRD analysis was $535 \mu \mathrm{m}$ for the sand mold sample and $146 \mu \mathrm{m}$ for the water-cooled brass sample, and shows a reduction of grain size by increasing the cooling rate. The conventional Babbitt alloys are being replaced by $\mathrm{Al}-\mathrm{Sn}$ alloys because of their superior mechanical properties; Al-Sn alloys can withstand substantially higher loads than the Babbitt alloys [4]. The ability to increase hardness by increasing the cooling rate has useful implications for the continued adoption of these alloys.

\section{Conclusions}

The effect of cooling rate on the microstructure and microsegregation in $\mathrm{Al}-30 \mathrm{wt} \% \mathrm{Sn}$ was studied by means of quantitative metallography and EPMA. The main conclusions drawn from this study were that with increasing cooling rate, the microstructure became finer and the minimum solute concentration increased to approximately four times the equilibrium value. Hardness also increased with cooling rate, mainly as a result of microstructure refinement.

\section{References}

1. K.S. Cruz, J.E. Spinelli, I.L. Ferreira, N. Cheung, A. Garcia, Microstructural development in $\mathrm{Al}-\mathrm{Sn}$ alloys directionally solidified under transient heat flow conditions. Mater. Chem. Phys. 109(1), 87-98 (2008)

2. ASM Handbook Committee, Alloy phase diagrams, in ASM Handbook. vol 3 (ASM International, Ohio, 1992)

3. K.S. Cruz, E.S. Meza, F.A.P. Fernandes, J.M.V. Quaresma, L.C. Casteletti, A. Garcia, Dendritic arm spacing affecting mechanical properties and wear behavior of $\mathrm{Al}-\mathrm{Sn}$ and $\mathrm{Al}-\mathrm{Si}$ alloys directionally solidified under unsteady-state conditions. Metall. Mater. Trans. A 41(4), 972-984 (2010)

4. T. Stuczynski, Metallurgical problems associated with the production of aluminum-tin alloys. Mater. Des. 18(4-6), 369-372 (1997) 
5. W.R. Osorio, J.E. Spinelli, N. Cheung, A. Garcia, Secondary dendrite arm spacing and solute redistribution effects on the corrosion resistance of $\mathrm{Al}-10 \mathrm{wt} \% \mathrm{Sn}$ and $\mathrm{Al}-20 \mathrm{wt} \% \mathrm{Zn}$ alloys. Mater. Sci. Eng. A 420(1-2), 179-186 (2006)

6. K.S. Cruz, I.L. Ferreira, J.E. Spinelli, N. Cheung, A. Garcia, Inverse segregation during transient directional solidification of an Al-Sn alloy: numerical and experimental analysis. Mater. Chem. Phys. 115(1), 116-121 (2009)

7. A.M. Kliauga, M. Ferrante, The influence of Sn on texture and grain growth of an A17Si0.3Mg alloy (A356) in the semi-solid state. Jornadas SAM-CONAMET-AAS, pp. 83-90 (2001)

8. T. Okamoto, K. Kishitake, Dendritic structure in unidirectionally solidified aluminum, tin, and zinc base binary alloys. J. Cryst. Growth 29(2), 137-146 (1975)

9. P. Padhi, S.K. Anand, D. Kar, S. Ghosh, S.C. Panigrahi, Modeling structure of Al-Sn Alloy. Mater. Sci. Forum 519-521, 1519-1524 (2006)

10. M.V. Cante, K.S. Cruz, J.E. Spinelli, N. Cheung, A. Garcia, Experimental analysis of the columnar-to-equiaxed transition in directionally solidified $\mathrm{Al}-\mathrm{Ni}$ and $\mathrm{Al}-\mathrm{Sn}$ alloys. Mater. Lett. 61(11-12), 2135-2138 (2007)

11. J.E. Spinelli, K.S. Cruz, M.V. Cante, A. Garcia, Primary dendrite arm spacing during transient directional solidification of $\mathrm{Al}$ alloys with low redistribution coefficients. Philos. Mag. Lett. 89(12), 779-786 (2009)

12. H.R. Kotadia, J.B. Patel, Z. Fan, E. Doernberg, R. SchmidFetzer, Processing of Al-45Sn-10Cu based immiscible alloy by a rheomixing process. Solid State Phenom. 141-143, 529-534 (2008)

13. H.R. Kotadia, E. Doernberg, J.B. Patel, Z. Fan, R. Schmid-Fetzer, Solidification of Al-Sn-Cu based immiscible alloys under intense shearing. Metall. Mater. Trans. A 40(9), 2202-2211 (2009)

14. H.R. Kotadia, J.B. Patel, Z. Fan, E. Doernberg, R. Schmid-Fetzer, Solidification and processing of aluminum based immiscible alloys, in Aluminum Alloys: Fabrication, Characterization, and Applications, vol II, ed by W. Yin et al. (The Minerals, Metals \& Materials Society, Warrendale, PA 2009), pp. 81-86

15. W. Zhiming, G. Haoran, Z. Guorong, G. Zhongquan, T. Xinying, Temperature-induced anomalous structural changes of Al-12 wt \% $\mathrm{Sn}-4 \mathrm{wt} \% \mathrm{Si}$ melt and its influence on as-cast structure. China Foundry 7, 138-142 (2010)

16. T. Marrocco, L.C. Driver, S.J. Harris, D.G. McCartney, Microstructure and properties of thermally sprayed Al-Sn-based alloys for plain bearing applications. J. Therm. Spray Technol. 15(4), 634-639 (2006)

17. C. Suryanarayana, T.R. Anantharaman, Solidification of aluminum-germanium alloys at high cooling rates. J. Mater. Sci. 5(11), 992-1004 (1970)

18. F. Hehmann, F. Sommer, B. Predel, Extension of solid solubility in magnesium by rapid solidification. Mater. Sci. Eng. A 125(2), 249-265 (1990)

19. D. Eskin, Q. Du, D. Ruvalcaba, L. Katgerman, Experimental study of structure formation in binary $\mathrm{Al}-\mathrm{Cu}$ alloys at different cooling rates. Mater. Sci. Eng. A 405, 1-10 (2005) 